\title{
Dynamique adaptative de diversification des cultures et recomposition des paysages ruraux à Santchou (Ouest-Cameroun)
}

\section{Hippolite Azaou (Doctorant, Géographie)}

Département de Géographie, FLSH, Université de Dschang, Bafoussam, Cameroun

Syndhia Mathe (PhD, Économiste)

CIRAD, UMR INNOVATION, Yaoundé, Cameroon, International Institute for Tropical Agriculture (IITA), Yaoundé, Cameroon

Denis Pompidou Folefack (Maitre de Recherche, Agroéconomiste)

CARBAP/IRAD, Njombé, Cameroun

\section{Maurice Tsalefac (Professeur des Universités, Climatologue)}

Département de Géographie, FLSH,

Université de Dschang, Dschang, Cameroun

\section{Résumé}

Au Cameroun, la libéralisation intervenue dans la filière café-cacao au début des années 1990 s'est accompagnée d'une paupérisation croissante des producteurs. Ces derniers ont adopté des stratégies d'adaptation diverses. Dans un contexte de crise caféière au Cameroun, le présent article vise à évaluer les stratégies paysannes de diversification des cultures de rente et leurs impacts dans la recomposition des paysages ruraux. Des enquêtes ont été menées auprès de 400 producteurs répartis dans les trois bassins de production de Santchou. Les résultats montrent que depuis la libéralisation des filières agricoles et la crise caféière qui a suivi, les producteurs dans leurs stratégies de survie ont diversifié les cultures de rente dans leurs exploitations familiales. Même si la caféiculture reste dominante, il faut relever que les cultures du cacao et du palmier à huile jadis rare connaissent une croissance fulgurante. Avec la saturation foncière, les cacaoyers et les palmiers sont non seulement insérés entre les lignes mais aussi, remplacent les plants de caféiers morts. Il en résulte une recomposition, voire une restructuration des paysages ruraux avec le développement des systèmes agroforestiers de multicultures caféierscacaoyers-palmiers. Pour la durabilité de ces nouveaux systèmes un accompagnement adapté de ces changements endogènes est nécessaire. 
Mots-clés : Dynamique adaptative, Diversification, Recomposition des paysages, Santchou

\title{
Adaptative Dynamics of Crop Diversification and Recomposition of Rural Landscapes in Santchou (West Region-Cameroun)
}

\section{Hippolite Azaou (Doctorant, Géographie)}

Département de Géographie, FLSH, Université de Dschang, Bafoussam, Cameroun

Syndhia Mathe (PhD, Économiste)

CIRAD, UMR INNOVATION, Yaoundé, Cameroon, International Institute for Tropical Agriculture (IITA), Yaoundé, Cameroon

Denis Pompidou Folefack (Maitre de Recherche, Agroéconomiste)

CARBAP/IRAD, Njombé, Cameroun

Maurice Tsalefac (Professeur des Universités, Climatologue)

Département de Géographie, FLSH,

Université de Dschang, Dschang, Cameroun

\begin{abstract}
In Cameroon, the liberalization that occurred in the coffee-cocoa sector in the early 1990s came alone with an increasing impoverishment of producers who had to develop adaptation strategies to survive. In the context of the coffee crisis in Cameroon, this article aims at assessing farmers' cash crops diversification strategies and their impacts on the recomposition of rural landscapes. Surveys were conducted with 400 farmers in the three Santchou production basins. The results show that since the agricultural commodity chains liberalization and the coffee crisis that followed, farmers have diversified their cash crops strategies on their family farms. Although coffee culture still dominates, cocoa and oil palm farming, which were once rare, are experiencing an explosive growth. With land saturation, not only are cocoa and palm trees planted between the rows, they are also, replacing dead coffee trees. As a result, we observe a recomposition, or even a restructuring of rural landscapes with the development of agroforestry systems of multiple cropping (that is coffee, cocoa and palms trees). In order to assure the sustainability of
\end{abstract}


these new systems, an appropriate support of these endogenous changes is essential.

Keywords: Adaptive dynamics, Diversification, Landscapes recomposition, Santchou

\section{Introduction}

Au Cameroun, près de $50 \%$ de la population vit en milieu rural et périurbain, avec l'agriculture comme principale activité (MINADER, 2006). C'est pourquoi, depuis l'indépendance, la politique économique, a accordé une place particulière au secteur agricole. Jusqu'au milieu des années 1980, la phase de planification consacrait à l'État, une prépondérance dans le déroulement de l'activité économique (Bella, 2009). À ce titre, des structures d'accompagnement des producteurs étaient mises en place comme le Fond National de Développement Rural (FONADER), l'Office Nationale de Commercialisation des Produits de Base (ONCPB) et les coopératives agricoles (Shepherd et al., 1999; Kamga, 2002; Fongang et al., 2017). Avec la crise économique des années 1980, une Nouvelle Politique Agricole (NPA) est mise en chantier représentant les grands traits du Programme d'Ajustement Structurel (PAS) et plus tard des Documents de Stratégie de Réduction de la Pauvreté (DSRP). On parlait désormais « de moins d'État et de plus de libéralisation » (Tchékoté et al., 2017).

Malheureusement pour de nombreux acteurs des filières agricoles, le désengagement de l'État consécutif à la politique de libéralisation, a été à l'origine de plusieurs problèmes vécus dans le monde rural (Shepherd et al, 1999, Kamgue, 2000, Fongang, 2008). Désormais confrontés à des défis considérables, les agriculteurs entreprenants et dynamiques, ont développé des capacités d'adaptation voire de réceptivité aux innovations. Une diversité des associations ou dissociations d'activités, des modalités d'adaptation aux contraintes naturelles et des modes d'organisation sociale ont conduit à une multiplicité de systèmes agraires (Courade et al., 2006). Dans les systèmes agroforestiers de Santchou, c'est la diversification des cultures de rente qui est développée comme principale stratégie d'adaptation. Les exploitations agricoles familiales sont prises d'assauts par les nouvelles cultures estimées plus lucratives. Sous l'impulsion des acteurs essentiellement endogènes, les innovations portent sur l'introduction du cacao (Théobroma cacao) et du palmier à huile (Elaeis guinneensis) jadis rares dans une localité où le café robusta (Coffea canephora), était considéré comme culture de base.

Dans un contexte de libéralisation des filières agricoles au Cameroun, ce travail vise à évaluer les stratégies paysannes de diversification des cultures de rente et leur impact dans la recomposition des paysages ruraux, en vue d'une agriculture durable. Comment les producteurs réagissent-ils dans ce 
contexte de crise? Quel est l'impact de ces stratégies paysannes sur l'évolution des paysages ruraux ?

\section{Méthodologie}

Cette étude a été menée à Santchou, un espace géographique situé entre le $5^{\circ} 7^{\prime}$ et le $5^{\circ} 33^{\prime}$ latitude Nord et entre le $9^{\circ} 5^{\prime}$ et le $10^{\circ} 7^{\prime}$ longitude Est. Il occupe la partie sud du département de la Menoua, région de l'OuestCameroun et s'étend sur $335 \mathrm{~km}^{2}$. C'est un cadre par excellence de la production agricole au regard de ses caractéristiques physiques et humaines. Pour mener ce travail, la démarche méthodologique essentiellement hypothético-déductive a été adoptée, combinant l'observation des faits, leurs interprétations et vérifications. A ce titre, la collecte des informations riches et fiables, a associé des outils et techniques qui ont suscité la participation des communautés tout au long du processus.

$\mathrm{Au}$ préalable, la littérature existante dans le domaine de la transformation agraire en milieu tropical a été valorisée par des écoles de pensée mettant en exergue des approches diverses. Par la suite, les enquêtes diagnostiques, les interviews et les observations directes sur le terrain ont permis de collecter les données primaires. À cet effet, un questionnaire et des guides d'entretien ont été élaborés et diligentés auprès des producteurs et autres acteurs de la filière. Après la subdivision de Santchou en trois bassins de production (Fombap, Fondonera et Sanzock), la sélection des villages a été fonction de leurs conditions physiques favorables à l'écologie de ses cultures. Pour le choix des producteurs, la technique d'échantillonnage au hasard a été utilisée pour enquêter 400 producteurs répartis dans les trois bassins de production.

Le traitement de ses données s'est fait par des logiciels MapInfo professional version 6.5 et Argis version 10.3.1 pour l'élaboration des cartes d'illustration; Excel 2010 et Statistical Package of Social Science (SPSS) version 20, pour saisir les données d'enquête de terrain et en faire des analyses statistiques descriptives et des fréquences. L'analyse des données a été faite par bassin de production notamment Fombap, Fondonera et Sanzock afin de mieux apprécier la réalité voire la spécificité de chaque localité.

\section{Résultats}

\section{Un vaste espace agricole en mutation à Santchou}

Avec une morphologie de plaine bordée de massifs, Santchou est une dépression topographique d'origine tectonique accompagnée d'un escarpement abrupt qui le sépare du plateau Bamiléké. Son climat équatorial de type camerounien, sa grande platitude, ses sols ferralitiques et colluviaux fertiles en font un excellent bassin de production agricole où prospèrent les cultures vivrières, maraichères et surtout de rente. 


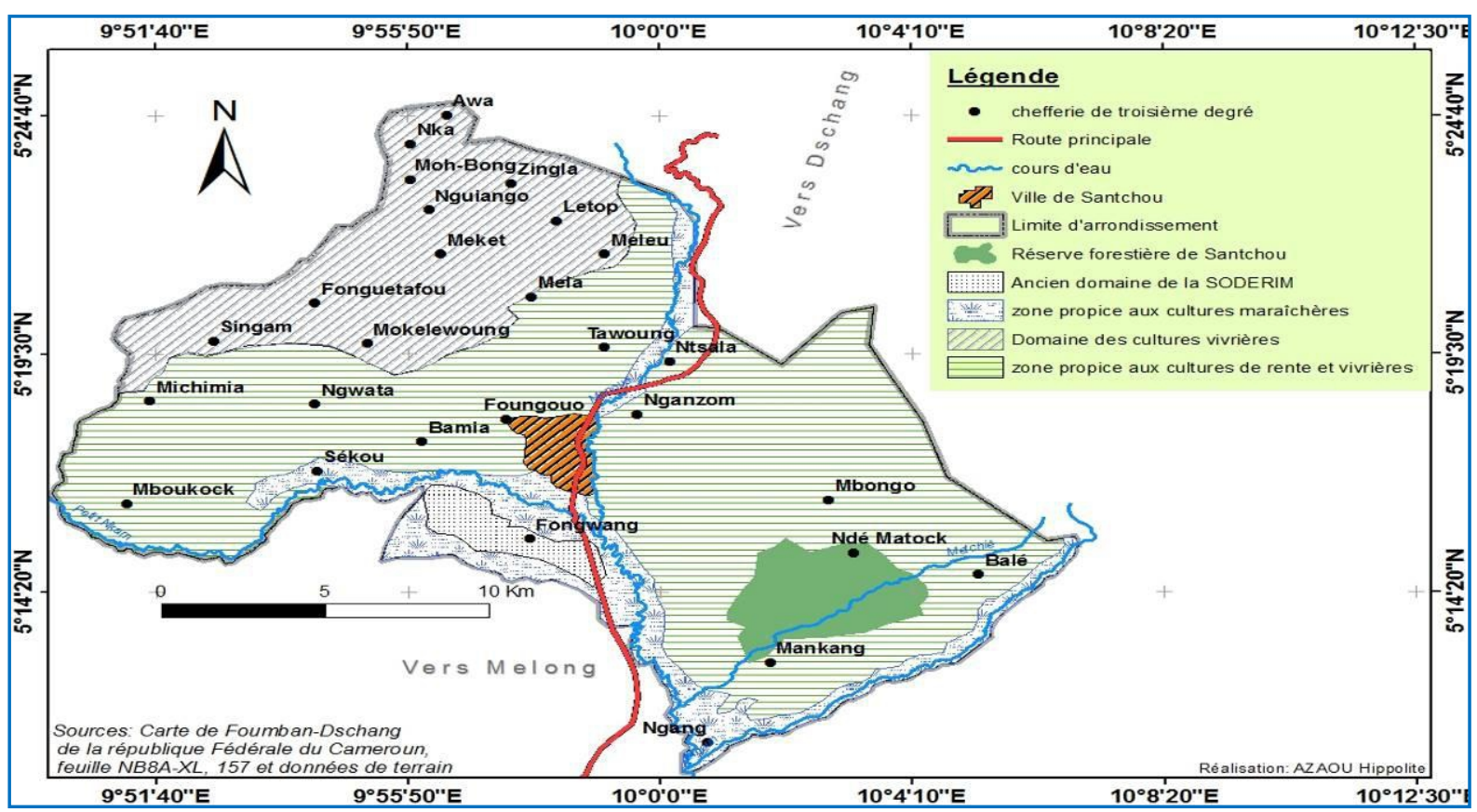

Figure 1 : Carte de l'espace agricole de Santchou

La figure 1 présente Santchou comme un vaste espace favorable à la production agricole. C'est un espace caféier, cacaoyer et palmier à huile qui s'étend de la grande plaine des Mbo aux versants bordiers et bute sur les altitudes supérieures à $1000 \mathrm{~m}$ sur lesquelles les cultures vivrières abondent. Aux abords des cours d'eau comme le Nkam et la Menoua, les cultures maraîchères se développent et parfois par intermittence. L'ancien domaine de la Société de Développement de la Riziculture de la plaine de Mbo (SODERIM) et les abords de la réserve forestière constituent aujourd'hui des zones pionnières de plus en plus soumises à une forte pression foncière. C'est dans ce vaste domaine aux conditions naturelles favorables à l'écologie des cultures de rente que de nombreuses exploitations agricoles familiales de 1,6 ha en moyenne par exploitant, abritent des cultures diverses qui façonnent l'espace.

$\mathrm{Au}$ regard des années d'expérience des producteurs par culture, il est clair que le caféier a été la plante à être premièrement adoptée par les chefs d'exploitation. Mais la libéralisation des filières café-cacao, viendra pousser les producteurs à développer d'autres cultures de leur choix. Depuis les années 1990 , près de $3 / 4$ des producteurs ont adopté des stratégies de diversification des cultures comme en témoigne la figure ci-après. 


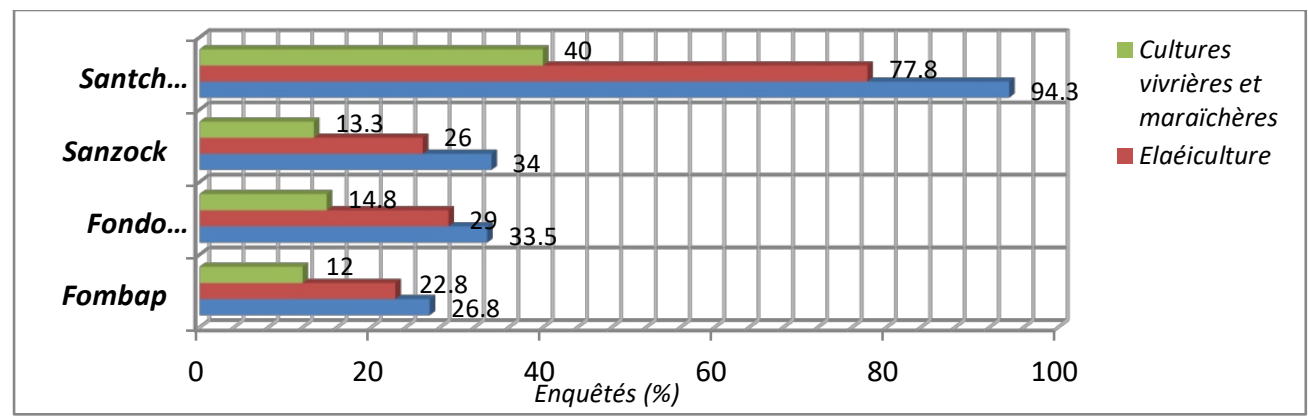

Figure 2: Principales cultures introduites dans les exploitations agricoles après la crise

La figure 2 montre les principales cultures de rentes adoptées par les producteurs de Santchou dans un contexte de crise. Dans tous les bassins de production, l'ordre de priorité des cultures est le même. Plus de $94 \%$ des producteurs de la localité ont adopté la cacaoculture contre $78 \%$ pour le palmier à huile et $40 \%$ pour les cultures vivrières (Djingembre, le manioc) et maraîchères. Deux temps forts marquent cette évolution des pratiques agricoles ainsi que de l'espace :

\section{L'ère de la fidélité à la caféiculture}

Elle va de l'introduction de la caféiculture à l'ouest Cameroun dans les années 30 à la libéralisation des filières agricoles (Ngapgue, 2007). Jusqu'en 1990, on pouvait dénombrer en moyenne 790 pieds de caféiers dans une exploitation agricole familiale de 1,6 ha en moyenne soit 1300 pieds/hectare. C'était pour les producteurs, la période faste ou les années de gloire du café. La caféiculture était essentiellement développée en monoculture et occupait la quasi-totalité des exploitations agricoles. Le café robusta trouvait, des conditions idéales de croissance et de fait, occupait l'essentiel des surfaces agricoles utiles. Au centre des exploitations agricoles familiales, il était donc la principale source de revenus monétaires des ménages agricoles. Pendant ce temps, la cacaoculture et l'élaéiculture n'étaient développées que par quelques rares paysans novateurs voire des pionniers. C'est pourquoi seulement 36 pieds de cacaoyers et 7 pieds de palmiers en moyenne étaient plantés par exploitation. Avec la crise caféière, il fallait faire face aux difficultés de trésorerie et contribuer à l'épanouissement du ménage agricole. D'où le développement des cultures de résilience qui ouvrira une nouvelle l'ère.

\section{L'ère de la diversification des cultures de rente après la crise caféière}

Elle commence dans les années 1990 et se poursuit en s'intensifiant aujourd'hui. Celle-ci a été caractérisée par le désintérêt progressif pour la caféiculture et une ouverture des exploitations vers des perspectives nouvelles avec la cacaoculture et l'élaéiculture. C'est donc l'ère de la transition 
agroécologique vers l'adoption d'une innovation. La caféiculture est concurrencée dans les exploitations agricoles, par la culture du cacao et du palmier à huile. Dans un environnement socioéconomique qui lui est peu favorable, la cacaoculture et l'élaéiculture deviennent des cultures de résilience et créent chez les producteurs, une grande émulation. Le dédain de la caféiculture s'accompagne de la régression des superficies de près de $50 \%$. A l'opposé, les surfaces occupées par les cacaoyers et les palmiers connaissent une évolution exponentielle de plus de $100 \%$ en près de trois décennie. Même si depuis 2011, les superficies régressent du fait des contraintes foncières à la production, le développement d'un système agroforestier caféier-cacaoyerpalmier devient porteur des espoirs de la paysannerie. Quelles sont stratégies de diversification mises sur pieds par les producteurs de Santchou?

\section{Des stratégies paysannes de diversification des cultures}

\section{La conservation des caféiers malgré la crise, une spécificité de Santchou}

La crise caféière consécutive à la politique de libéralisation des filières agricoles des années 1990, s'est accompagnée d'une paupérisation croissante des producteurs. Dans de nombreux bassins de production caféier de l'Ouest Cameroun, notamment Bafou et Foumbot, les caféiers arabica sont vites arrachés, remplacés par le vivrier marchand et le maraicher, jugés plus lucratifs. À l'évidence, le dédain pour la caféiculture est manifeste. Mais, les producteurs de Santchou s'y accrochent en y associant les cacaoyers et les palmiers à huile. D'où l'épineuse question de savoir, pourquoi ces producteurs, n'abandonnent-ils pas la caféiculture pourtant en crise? Le tableau ci-après apporte quelques éléments de réponse.

Tableau 1 : Les raisons de la conservation des caféiers dans les EFA de Santchou malgré la crise

\begin{tabular}{lllllll}
\hline \multicolumn{7}{c}{ Raisons de la conservation des caféiers } \\
\cline { 3 - 7 } & & $\begin{array}{l}\text { Apport pécuniaire } \\
\text { du café toujours } \\
\text { nécessaire }\end{array}$ & $\begin{array}{l}\text { Diversification } \\
\text { des périodes de } \\
\text { récoltes }\end{array}$ & $\begin{array}{l}\text { Question } \\
\text { de } \\
\text { nostalgie }\end{array}$ & $\begin{array}{l}\text { Avenir } \\
\text { incertain des } \\
\text { autres cultures }\end{array}$ & $\begin{array}{l}\text { Caféiers comme } \\
\text { abris pour les } \\
\text { jeunes cacaoyers }\end{array}$ \\
\hline \multirow{2}{*}{ Fombap } & Effectif & 99 & 72 & 17 & 17 & 11 \\
& Pourcentage (\%) & 24,8 & 18 & 4,3 & 4,3 & 2,8 \\
\multirow{2}{*}{ Fondonera } & Effectif & 100 & 105 & 18 & 17 & 10 \\
& Pourcentage (\%) & 25 & 26,3 & 4,5 & 4,3 & 2,5 \\
\multirow{2}{*}{ Sanzock } & Effectif & 117 & 108 & 19 & 18 & 11 \\
& Pourcentage (\%) & 29,3 & 27 & 4,8 & 4,5 & 2,8 \\
\hline \multirow{2}{*}{ Santchou } & Effectif & $\mathbf{3 1 6}$ & $\mathbf{2 8 5}$ & $\mathbf{5 4}$ & $\mathbf{5 2}$ & $\mathbf{3 2}$ \\
& Pourcentage (\%) & $\mathbf{7 9}$ & $\mathbf{7 1 , 3}$ & $\mathbf{1 3 , 5}$ & $\mathbf{1 3}$ & $\mathbf{8}$ \\
\hline
\end{tabular}

Il ressort du tableau 1 que malgré la crise, les producteurs trouvent des raisons de conserver les caféiers dans leurs EFA. Plus de 3/4 soit $79 \%$ des producteurs, reconnaissent que le café reste et demeure pour le ménage agricole, une source de revenus indéniable. C'est pourquoi dans la localité, beaucoup d'évènements traditionnels sont programmés par rapport aux 
campagnes caféières. Pour d'autres $(71,3 \%)$, le maintien de la caféiculture s'inscrit dans la logique de diversification des périodes de récoltes donc, des sources de revenus. Ils ont justement compris l'importance de l'association des revenus issus des différentes cultures dans la vie du ménage. De plus, quelques producteurs nostalgiques (13\%) surtout les plus âgés, ont en souvenance les années glorieuses du café tandis que d'autres plutôt anxieux, ne font pas entièrement confiance aux nouvelles cultures de rente au regard des incertitudes sur leur avenir dans un contexte socioéconomique en mutation. Pour un petit nombre d'innovateurs conscients ( $8 \%$ ), les caféiers constituent un meilleur abri pour les jeunes cacaoyers. Ce qui débouche sur une recomposition des exploitations caféières existantes.

\section{La transformation des exploitations caféières existantes}

Avec la saturation foncière, jusqu'à $3 / 4$ d'exploitants familiaux de Santchou, n'ont plus accès à de nouvelles terres pour créer ou étendre leurs plantations. Ce sont donc les exploitations caféières existantes qui sont essentiellement visées et par conséquent transformées. Mise en évidence par plus de $77 \%$ des producteurs, c'est une stratégie majeure de recomposition des paysages agraires qui se développe suivant les techniques ci-après :

Tableau 2: Techniques de recomposition des exploitations caféières existantes

\begin{tabular}{lllll}
\hline & \multicolumn{3}{l}{ Techniques de recomposition des exploitations caféières } \\
\cline { 3 - 5 } & & $\begin{array}{l}\text { Par insertion des } \\
\text { cacaoyers et palmiers } \\
\text { entre les caféiers }\end{array}$ & $\begin{array}{l}\text { Par remplacement des } \\
\text { caféiers morts par des } \\
\text { cacaoyers et palmiers }\end{array}$ & $\begin{array}{l}\text { Par destruction des } \\
\text { caféiers pour planter } \\
\text { cacaoyers et palmiers }\end{array}$ \\
\hline \multirow{2}{*}{ Fombap } & Effectif & 118 & 75 & 3 \\
& Pourcentage (\%) & 29,5 & 18,8 & 0,8 \\
\multirow{2}{*}{ Fondonera } & Effectif & 132 & 89 & 0 \\
\multirow{2}{*}{ Sanzock } & Pourcentage (\%) & 33,0 & 22,3 & 0,0 \\
& Effectif & 136 & 73 & 2 \\
\multirow{2}{*}{ Santchou } & Pourcentage (\%) & 34 & 18,3 & 0,5 \\
& Effectif & $\mathbf{3 8 6}$ & $\mathbf{2 3 7}$ & $\mathbf{5}$ \\
& Pourcentage (\%) & $\mathbf{9 6 , 5}$ & $\mathbf{5 9 , 3}$ & $\mathbf{1 , 3}$ \\
\hline
\end{tabular}

Il découle du tableau 2 que dans la diversification des cultures de rente, trois principales techniques de recomposition voire de déstructuration des champs de caféiers sont mises en exergue. D'emblée, plus de $96 \%$ des producteurs procèdent par insertion des nouvelles cultures entre les caféiers. De plus, d'aucuns soit 59,3\% remplacent des caféiers morts par les nouvelles cultures tandis qu'une proportion bien que marginale $1,3 \%$ va même plus loin en détruisant les caféiers. D'une exploitation à dominance caféière, on passe progressivement à un champ multiculturel dans lequel, certains caféiers ne sont plus que des témoins. Les photos ci-après illustrent en image cette décomposition des exploitations caféières. 


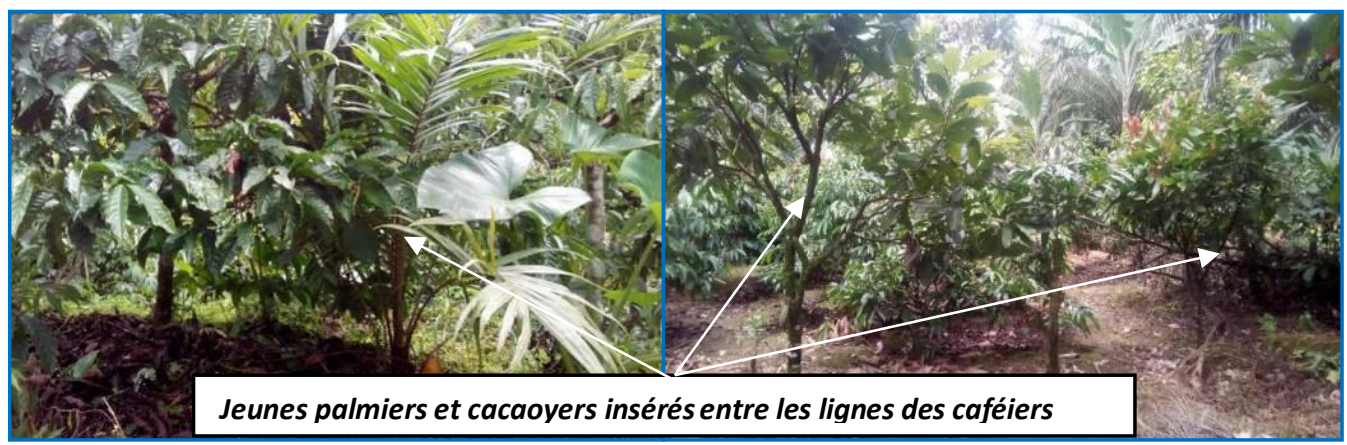

Planche photo 1 : Insertion des palmiers et des cacaoyers entre les lignes des caféiers

D'une exploitation à l'autre, les nouvelles cultures sont développées à l'intérieur des caféiers déjà existants. A des intervalles plus ou moins réguliers, les jeunes plants de cacaoyers et de palmiers à huile sont insérer entre les lignes. Au fil du temps, certaines exploitations caféières se transforment radicalement, car dans leurs croissances, les nouvelles cultures finissent par étouffer les caféiers. D'une exploitation à dominance caféière, on passe progressivement à un champ multiculturel caféiers-cacaoyers-palmiers dans lequel, certains caféiers ne sont plus que des témoins. A côté, on observe un autre système de diversification par la création de nouvelles exploitations agricoles.

\section{La création de nouvelles plantations cacaoyers-palmiers}

La stratégie de diversification par la création de nouvelles exploitations, restent fortement tributaire des disponibilités foncières des producteurs. Même si plus de $51 \%$ des producteurs procèdent à la création de nouvelles exploitations, seulement $1 / 4$ sont des propriétaires terriens disposant encore des terres pour étendre leurs superficies. Devant cette rareté des terres en friche, les abords de la réserve forestière de Santchou, l'ancien domaine de la SODERIM et les terres inondables sont aujourd'hui prises d'assaut par les cultures de rente. Ce sont de nouvelles zones pionnières où se développe un autre système agroforestier cacaoyers-palmiers sans les caféiers.

Ces nouvelles exploitations familiales symbolisent la rupture avec la caféiculture. Si la libéralisation des filières agricoles permet aux producteurs de développer les cultures de leurs choix, la crise caféière a entrainé le dédain pour la caféiculture. Pour certains producteurs, il faut progressivement tourner la page. Dans les anciennes exploitations agricoles, les caféiers sont conservés en association avec d'autres cultures. Mais à la moindre possibilité de création de nouvelles plantations, ce sont les cacaoyers et les palmiers à huile qui sont sollicités pour occuper les espaces cultivés. Un prototype de nouvelles exploitations symbolisant la rupture progressive avec la caféiculture robusta. Ce sont surtout des exploitations de plaine qui se développent sur de nouvelles 
terres conquises essentiellement dans des zones inondables. Il est évident de constater que dans ces nouvelles plantations, les caféiers ne sont plus plantés d'où le développement d'un nouveau système cacaoyers-palmiers.

Bien plus, d'autres stratégies de diversification des cultures de rente existe à Santchou. A défaut de disposer de terres pour créer de nouvelles plantations, une proportion non négligeable de producteurs soit $21 \%$ achètent les exploitations déjà créées tandis que 5,8\% procèdent par location ou métayage. Dès lors, les exploitations caféières achetées ou louées subissent les mêmes transformations par l'insertion des autres cultures de rente. Peu importe le comportement des producteurs, le paysage agraire de Santchou n'est plus le même. Quel est l'impact de ces stratégies paysannes sur les paysages ruraux ?

\section{Une recomposition de l'espace agraire de Santchou}

Malgré son déclin, le café robusta est loin de disparaitre dans le paysage agraire de Santchou, car quelques raisons non des moindres prolongent encore sa durée de vie. Mais la monoculture du café qui a prévalu avant la crise caféière cède de la place à un système d'association des cultures. Il s'en suit une recomposition voire une restructuration des paysages agraires avec le développement d'un système agroforestier de multiculture caféier-cacaoyerpalmier à huile très vital pour la survie de la paysannerie et des agroécosystèmes. Le tableau suivant dresse une classification de ces exploitations agricoles suivant les principales cultures adoptées depuis la libéralisation des filières agricoles.

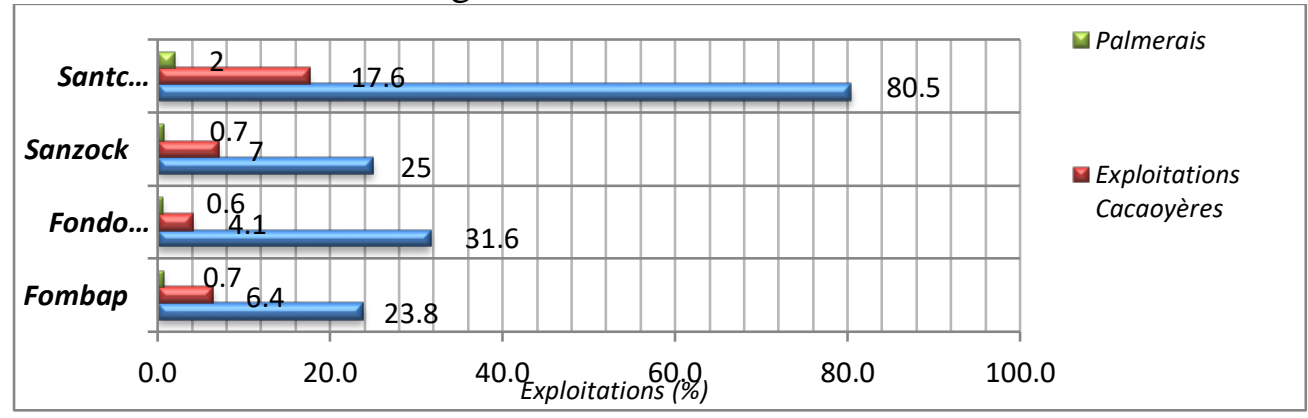

Figure 3: Une nouvelle typologie des exploitations agricoles à Santchou

Il ressort du la figure 3 que la diversification des cultures de rente dans les exploitations familiales de Santchou laisse apparaitre de nouvelles formes de recomposition du paysage agricole. Sur près de 1024 exploitations familiales recensées dans le cadre de cette étude, 80,5\% sont mixtes (caféiercacaoyer-palmier) contre $19 \%$ monospécifiques. Dans tous les bassins de production, la tendance est la même. Les exploitations familiales mixtes occupant l'essentiel du paysage agricole, symbolisent la discontinuité du système voire le recul de la monoculture du café. Elles représentent $31,6 \%$ à 
Fondonera, $25 \%$ à Sanzock et 23,8 \% à Fombap. Les exploitations monospécifiques sont moins nombreuses respectivement 17,6\% en cacaoyers et $2 \%$ en palmerais. Elles traduisent quant à elles, une rupture avec la caféiculture robusta.

\section{Un système de discontinuité par association des cultures}

Avec la saturation foncière, le système caféicole est mis économiquement en concurrence avec les autres cultures dans les exploitations de la localité : on parle de recomposition des paysages ruraux par la diversification. Ainsi, les exploitants familiaux maintiennent des caféiers plus ou moins entretenus qu'ils associent avec d'autres cultures comme le cacao, le palmier à huile, les arbres fruitiers et même les cultures vivrières. De ces cultures associées, le cacao et le palmier à huile occupent une place de choix. Ce sont des cultures de résilience qui, combinées aux caféiers développent des exploitations agricoles familiales de multicultures caféierscacaoyers-palmiers jadis rares dans la localité.

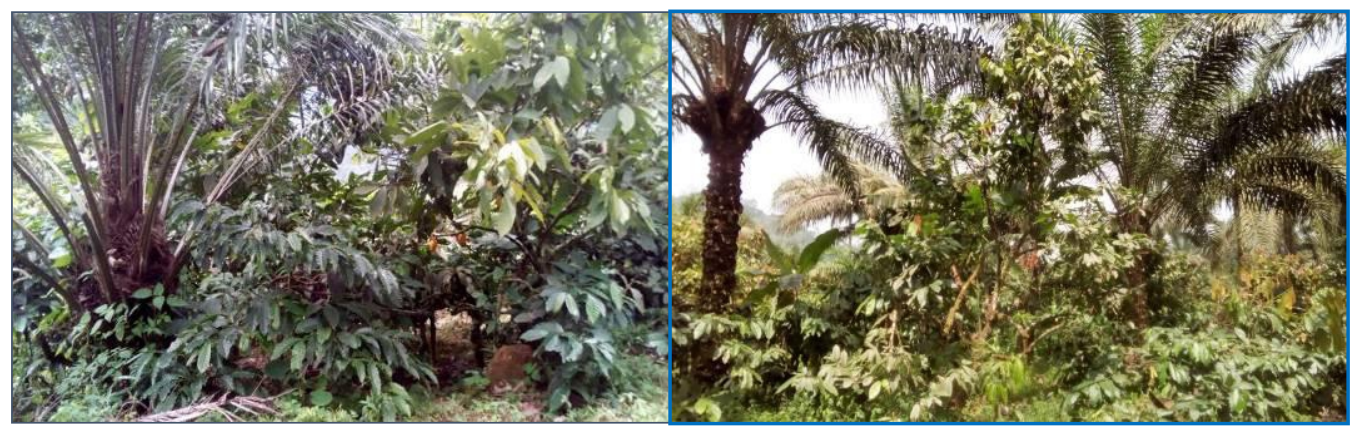

Planche photo 2 : Des exemples de discontinuité avec des systèmes agroforestiers complexes

La planche photo 3 présente deux exploitations agricoles caractéristiques d'une discontinuité spatiale à Santchou qui développe des systèmes agroforestiers complexes. Ces photos présentent une association à trois cultures de rente: caféiculture, cacaoculture et élaéiculture. Très répandus dans la localité depuis la crise caféière, ce système d'association cultural représente $80,5 \%$ des exploitations existantes. Avec la crise caféière, les producteurs de Santchou ont compris la nécessité de diversifier les cultures et par conséquent, de bénéficier d'une variété des productions donc de source de revenus. D'un système de monoculture robusta à une multiculture, les paysages ruraux de Santchou ont considérablement évolué. Partout, les producteurs innovent en adoptant une manière de faire différente. Certaines de ces innovations transforment même radicalement les paysages donnant lieu à une rupture totale avec la caféiculture. 


\section{Un système de rupture avec la caféiculture robusta}

Parler de rupture dans le système agricole de Santchou, c'est reconnaitre l'existence d'un changement de paradigme vers un modèle agricole totalement différent. Si la caféiculture robusta trouvait à Santchou, des conditions idéales de croissance avant la libéralisation des filières agricoles des années 1990, aujourd'hui, la situation est tout autre. Dans les exploitations agricoles familiales, les producteurs ont innové en adoptant des nouvelles cultures. Dans bien des exploitations agricoles, les cacaoyers et les palmiers à huile substituent entièrement les caféiers. Dans l'ensemble de la localité, $19 \%$ des exploitations existantes ne contiennent plus de caféiers. Au centre de cette dynamique, $1,3 \%$ de producteurs ont quasiment rompu avec les caféiers. Dans leurs exploitations, les caféiers en crise sont détruits et remplacés par les cacaoyers et les palmiers à huile. Par contre, environ $1 / 4$ des producteurs, disposant encore des terres en friche ont développé directement la cacaoculture et l'élaéiculture. Il s'en suit un système de rupture total avec la caféiculture robusta qui peut revêtir plusieurs formes telle qu'illustré par les photos ci-après.

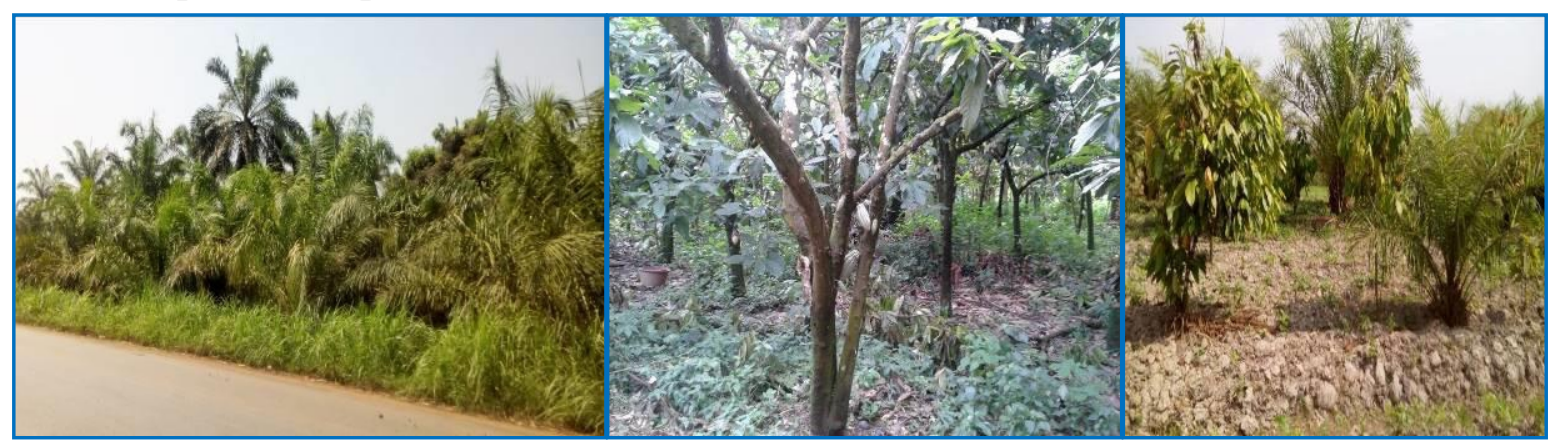

Planche photo 3 : Des exemples de rupture avec des exploitations sans caféiers

Ces photos illustrent les formes de rupture du système caféier. Les deux premières images représentent des exploitations monospécifiques de cacaoyers et de palmiers. Même si la cacaoculture en monospécifique est de plus en plus répandue, les palmeraies quant à elles sont rares. Mais, tout au long de la route Santchou-Melong, elles donnent les allures de véritables "palm belt» sur l'ancien domaine de la SODERIM. De plus, d'autres exploitations sont mixtes avec une association de la cacaoculture et de l'élaéiculture sans les caféiers. Toutes ces plantations quasi inexistantes il y'a une vingtaine d'année, caractérisent aussi fort bien la localité et structurent non seulement les paysages ruraux mais l'ensemble des agroécosystèmes. 


\section{Les contraintes des producteurs dans leurs stratégies}

A Santchou, la diversification des cultures de rente procure aux producteurs, des dividendes économiques et sociaux. Le système caféiercacaoyer-palmier qui en résulte transforme non seulement le paysage agraire, mais aussi les habitudes des populations. Partout, c'est la grande émulation. Mais, cet engouement autour des nouvelles cultures se heurte tout de même à des contraintes de divers ordres :

\section{Des contraintes foncières saisissantes}

Malgré la volonté d'expansion des exploitations agricoles. Plus de $3 / 4$ des producteurs souhaitent désormais étendre leurs superficies mais, les disponibilités foncières sont de plus en plus limitées. La difficulté d'accès à la propriété se pose. Cette problématique est commune aux producteurs d'Afrique Subsaharienne. « En raison de la forte convoitise pour des activités économiques, les terres agricoles sont au centre de nombreux enjeux politiques, économiques, socioculturels et environnementaux (Houdeingar, 2009). Ainsi, les cas de succession, d'achat et de location des terres étant modestes, il s'en suit la transformation des exploitations existantes par insertion des nouvelles cultures ainsi que la conquête des zones parfois inappropriées. A cette insuffisance de plus en plus criarde des espaces libres ou en friche pour l'extension des exploitations se greffent de nombreux problèmes d'ordre naturel.

\section{Des contraintes naturelles fortes}

Avec les changements climatiques, les inondations, les sols hydromorphes, les contraintes naturelles à cette dynamique paysanne sont réelles. Du fait de leurs impacts potentiels sur la production agricole, les changements climatiques représentent une des grandes préoccupations du monde rural. Ils bousculent le calendrier agricole, le rendant non maîtrisable, avec l'apparition fréquente et non cyclique des maladies et ravageurs souvent difficiles à contrôler (CTSCCC, 2014, BAD, 2016). À cela s'ajoute près de 36 $\%$ des producteurs qui souffrent de l'humidité des sols de plaine comme en témoigne la figure ci-après. 


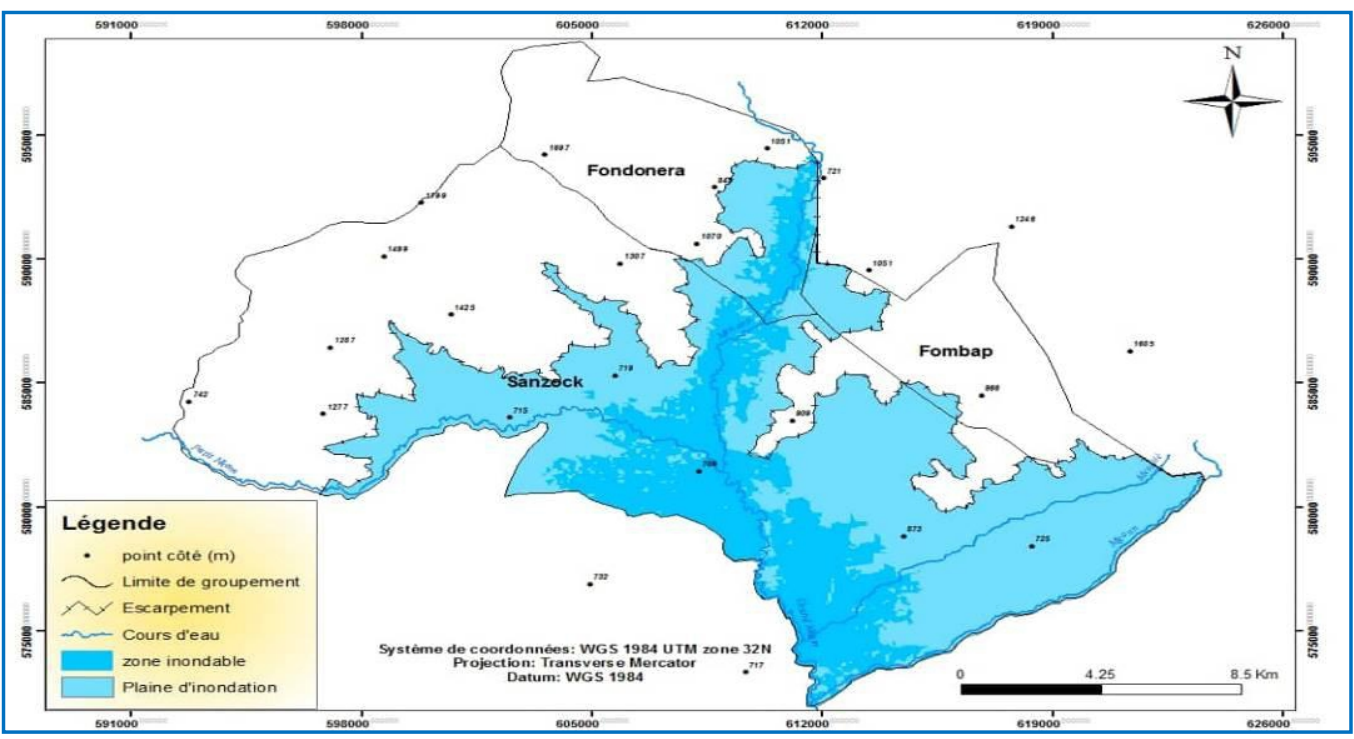

Figure 4: Carte de la répartition des sols hydromorphes

La figure 4 est une carte physique qui présente une grande plaine d'inondation d'altitude variable entre $700-800 \mathrm{~m}$ qui bordent l'escarpement de Foreké. C'est la zone de prédilection de la diversification des cultures où de nombreuses exploitations agricoles se développent. Dans cette plaine, une zone inondable aux abords des cours d'eaux est aujourd'hui prise d'assaut par des exploitants agricoles en quête des terres cultivables. Cet espace est régulièrement inondé et, l'omniprésence de l'eau constitue un obstacle au développement des cultures.

\section{De nombreuses contraintes techniques et socioéconomiques}

Selon leur gravité, les contraintes techniques et socioéconomiques ont un impact négatif sur la production agricole. Il s'agit des insectes nuisibles, de la pression parasitaire du manque d'engrais et produits phytosanitaires pour l'entretien des vergers et de la production. Ainsi, les pertes provoquées par les maladies, les insectes et les ravageurs sont évaluées à plus de la moitié de la production potentielle. Les dégâts les plus importants sont dus à la famille d'insectes piqueurs de morphologies diverses. Les piqûres, principalement sur les cabosses et jeunes rameaux se traduisent par des nécroses pouvant entraîner la mort de ces derniers. Faute de soins, toute la frondaison peut être détruite (Kouadjo et al, 2002). De plus, le manque de moyen pour l'achat des intrants agricoles, les difficultés d'accès au marché après la récolte et le déficit de vulgarisation ainsi que de formation constituent les principales contraintes socioéconomiques. 


\section{Discussion}

Avec la crise caféière des années 1990 et la politique de libéralisation qui s'en est suivie, le secteur agricole de l'Ouest Cameroun a connu de profondes mutations (Gafsi et al., 2007). ^̀ Santchou, les difficultés économiques des producteurs vont fortement contribuer à une diversification des cultures comme une stratégie de résilience. Sous la houlette des producteurs entreprenants et innovateurs, un nouveau système agricole, porteur des espoirs de survie de toute la paysannerie voit le jour. Partout, l'émulation est grande autour du système caféier-cacaoyer-palmier. De l'insertion des cacaoyers et des palmiers entre les caféiers, à la création de nouvelles exploitations, on assiste de plus en plus à une restructuration de l'espace agraire. Ainsi, « la caféiculture, mode de production dominant sur les hautes terres de l'ouest Cameroun, a contribué à l'émergence d'une nouvelle territorialisation de l'espace » à la fin des années 1980 (Uwizeyimana, 2009). Depuis lors, cette prépondérance du café dans les pratiques agricoles est de plus en plus remise en cause depuis les années 1990. L'irruption des autres cultures dans les exploitations agricoles familiales a donné lieu à un paysage agraire complètement remodelé (Uwizeyimana, 2009).

Certes, les cultures adoptées sont différentes selon les localités. Mais, on constate tout de même une homogénéité dans la stratégie de diversification des cultures dans ce contexte de crise au Cameroun. Les producteurs de Santchou sont comparables à leurs homologues des zones cotonnières, cacaoyères et caféicoles suivantes :

- Face à la crise qu'a connue la filière cotonnière camerounaise depuis les années 2000, les producteurs de la zone cotonnière du NordCameroun tout comme ceux de Santchou, doivent prendre en permanence des décisions concernant la production (choix technique), mais également sa mise en valeur: négociation du prix, commercialisation et positionnement sur le marché international (choix économiques). Ainsi, ils «ont développé des stratégies multifonctionnelles, avec un accent sur la diversification des cultures. Certains paysans ont abandonné la culture du coton, d'autres l'ont maintenu en attendant de voir, tandis que d'autres ont continué à s'y investir $\gg$. Cette nouvelle gouvernance des filières cotonnières, avec des acteurs économiques responsables de leurs outils économiques, crée des conditions favorables pour promouvoir la productivité en innovant dans de nouvelles techniques de production et dans de nouveaux produits (Folefack, 2010).

- Face à la crise cacaoyère consécutive à la libéralisation des filières agricoles des années 1990, les producteurs du Centre-Cameroun tout comme ceux de Santchou, ont montré une réelle capacité à s'adapter aux changements de leur environnement socio-économique. Ils ont mis 
en place, des systèmes de culture leur permettant de produire les denrées agricoles toute l'année et de subvenir aux besoins alimentaires de la famille. Dans l'ensemble, ils «tentent la diversification des produits pour sécuriser leurs revenus monétaires (Losh et al., 1991, Sanchez 2001, Tefang et al., 2008). Les arbres fruitiers sont associés aux cacaoyers tandis que le vivrier marchand offre de nouvelles opportunités de revenus. D'aucuns maintiennent leur verger avec un entretien minimum, en y associant d'autres cultures, en espérant pouvoir relancer la production quand les conditions redeviendront plus favorables (Tefang et al., 2008).

- Dans le Moungo, les producteurs ont placé le système caféicole en concurrence avec les autres systèmes de culture pour développer des innovations culturales. Les planteurs pluriactifs qui ont accès à des capitaux extérieurs pour investir, ont changé de système. Le café a été arraché et substitué par d'autres spéculations de rente cultivées intensivement (ananas, papaye, poivre, fleurs). D'aucuns ont préservé le système avec entretien du café tandis que d'autres l'ont diversifié en y associant des cultures densifiées (Sanchez, 2002). De plus, les planteurs aux revenus agricoles totalement basés sur le café ont intensifié le facteur terre pour maximiser les recettes agricoles à l'échelle de l'exploitation par le développement de l'agriculture de subsistance. Ici, c'est une densification généralisée des productions pérennes et vivrières au sein des caféiers (Sanchez, 2002).

- Sur les hautes terres de l'Ouest, « le caféier fragilisé par l'ouverture des marchés, a cédé de plus en plus la place à d'autres cultures » (Uwizeyimana, 2009). Ce fait a entrainé, à Foumbot, une mutation des pratiques agricoles avec l'essor du vivrier marchand. Il s'agissait là d'une recomposition de l'espace agricole par « une orientation de l'agriculture vers le maraîchage et le vivrier marchand » (Ngapgue, 2007). Dans un contexte socioéconomique d'incertitude lié à la libéralisation des filières agricoles, certains caféiculteurs de la localité de Bafou «se sont livrés à l'arrachage de leurs caféiers » (Kamgue, 2000).

Malgré les contraintes à la diversification des cultures de rente à Santchou, le développement du système café-cacao-palmier est désormais porteur de beaucoup d'espoir pour la paysannerie ainsi que pour les agroécosystèmes.

\section{Conclusion}

Ce travail renseigne sur les stratégies paysannes de diversification des cultures de rente et leurs impacts dans la recomposition des paysages ruraux. Les résultats montrent que depuis la crise caféières des années 1990, les 
exploitations agricoles traditionnellement caféières, sont prises d'assaut par les cacaoyers et les palmiers à huile adoptés comme cultures de résilience. Dans le bassin de production de Santchou, plusieurs stratégies d'adaptation sont mises en évidence. Les cacaoyers et les palmiers sont insérer entre les lignes des caféiers et occupent dans certains cas, les nouvelles exploitations. Si les superficies de caféiers stagnent, ceux des cacaoyers et des palmiers connaissent par contre, une croissance fulgurante. D'une exploitation à dominance caféière, on passe progressivement à un champ multiculturel dans lequel, certains caféiers ne sont plus que des témoins.

De plus, ce travail relève que l'adoption des innovations a contribué à une recomposition, voire restructuration de l'espace agraire avec le développement des exploitations de multicultures caféiers-cacaoyers-palmiers et de quelques plantations monospécifiques à base du cacao et du palmier. Ce qui corrobore ces propos de Ruiz et al (2005), pour qui, « l'agriculture aura largement contribué à façonner les paysages ruraux. Par ses pratiques, elle aura modelé les formes des territoires, modifié ses contours ». Malgré les contraintes à la diversification, le système café-cacao-palmier porte désormais les espoirs de toute une paysannerie. C'est pourquoi, dans la perspective de promotion d'une agriculture durable à Santchou, la problématique de la durabilité de ce nouveau système doit être mise en évidence. Ce qui permettrait selon Achancho (2012), d'amorcer la transition d'une filière de subsistance à une filière professionnalisée, durable et économiquement profitable pour l'ensemble des acteurs surtout les producteurs.

Au terme de cette étude, pour la durabilité des systèmes de production multiculture caféiers-cacaoyers-palmiers, l'on recommande : L'application par les producteurs, des Bonnes Pratiques Agricoles (BPA) pour une production quantitative et qualitative; le développement d'un Système Agroforestier (SAF) pour la durabilité et la rentabilité des agroécosystèmes ; la promotion de la consommation locale comme stimulant pour la croissance économique ; le rôle de catalyseur de l'État dans la formation, la vulgarisation et l'accès aux intrants pour un meilleur accompagnement de cette dynamique.

\section{References:}

1. Achancho, V., (2012), Le rôle des organisations paysannes dans la professionnalisation de l'agriculture en Afrique subsaharienne : le cas du Cameroun. Thèse de Doctorat en Sociologie. AgroParisTech, 417 p.

2. BAD, (2016). Nourrir l'Afrique, Stratégie pour la transformation de l'agriculture africaine 2016 -2025, 80 p.

3. Bella H., (2009). Agriculture et croissance économique au Cameroun. In www.memoireonline.com. Consulté le 10 juin 2017. 
4. CIRAD, (2010). Inventer une agriculture écologiquement intensive pour nourrir la planète, Améliorer les systèmes agroforestiers en zone tropicale humide, Cas des cacaoyers et des caféiers.

5. CTSCCC, (2014). Plan de Relance et de Développement des Filières Cacao et Café du Cameroun. Horizon 2020, Projet, Août, 106 p.

6. Courade, G., \& Deveze J-C., 2006. Introduction thématique, des agricultures africaines face à de difficiles transitions, cairn.info, « Afrique contemporaine $», \mathrm{n}^{\circ} 217 \mid$ pages 21 à 41

7. Faure, G., (2007). L'exploitation agricole dans un environnement changeant: innovation, aide à la décision et processus d'accompagnement. Économie et finances. Université de Bourgogne, 222 p.

8. Fongang Fouepe, G. H. (2008). Les mutations du secteur agricole Bamiléké (Cameroun) étudiées à travers ses acteurs : Une analyse à partir des localités de Fokoué et de Galim: Humanities and Social Sciences. AgroParisTech, 416 p.

9. Fongang Fouepe, G. H., Nguekeng, B., \& Kenfack Essougong, U.-P. (2017). Crise caféière et déclin des coopératives agricoles à l'Ouest Cameroun: La difficile relance de la Coopérative agricole des Planteurs de la Menoua (CAPLAME). International Journal of Innovation and Applied Studies, Vol. 19 No. 3 Feb. 2017, 14 p.

10. Folefack, D. P. (2010). Coordination des acteurs dans un contexte de crise : le cas de la filière coton au Cameroun, Thèse de doctorat en économie, Université de Rennes 2 Haute Bretagne, 292 p.

11. Gafsi M., Dugue, P., Jamin, J.-Y., \& Brossier, J. (Cord), (2007). Exploitations agricoles familiales en Afrique de l'Ouest et du Centre. Enjeux, caractéristiques et éléments de gestion, Collection Synthèses, CTA, Éditions Quæ, France, 475 p.

12. Houdeingar, D. (2009). L'accès à la terre en Afrique subsaharienne. L'accès à la terre et ses usages: variations internationales, Rencontres Lascaux 8 \& 9 Jun 2009, Nantes, France, 22 p.

13. Kamgue Tagne, P. M. (2000). Déprise caféière et modification dans l'utilisation et la couverture du sol, le cas de l'interfluve Ndouzem (Bafou)-Mbou (Baleng), Département de géographie, Université de Dschang.

14. Kouadjo, J. M., Keho, Y., Mosso, A., Toutou, K., G., Nkamleu, G., B., Gogkowski, J., (2002), Production et offre du cacao et du café en Côte d'Ivoire, Programme Pour la Durabilité des Cultures Arbustives, Rapport d'enquête, 128 p.

15. Losch, B., Fusillier, J. L., \& Dupraz, P. (1991). Stratégies des producteurs en zone caféière et cacaoyère du Cameroun. Quelles 
adaptations à la crise ? Montpellier France, CIRAD-DSA, Coll. Documents systèmes agraires, $\mathrm{N}^{\circ} 12,252 \mathrm{p}$.

16. MINADER, (2006). Stratégie de Développement du Secteur Rural (SDSR), synthèse du volet agriculture et développement rural, juillet, $71 \mathrm{p}$.

17. Ngapgue, J. N. (2007). Le maraîchage et le vivrier marchand comme solution à la crise caféière dans la région de Foumbot? Thèse de Doctorat $\mathrm{Ph} / \mathrm{D}$., Université de Dschang (Cameroun), $597 \mathrm{p}$.

18. Ruiz, J., \& Domon, G. (2005). Les paysages de l'agriculture en mutation. In : Poullaouec-Gonidec, P., Domon, G. et S. Paquette (Éds.). Paysages en perspective. Presses de l'université de Montréal, série « Paysages », Montréal, pp. 47-97.

19. Sanchez, S. (2002). Synthèse analytique sur l'évolution des systèmes de culture caféiers dans quatre zones de production du Moungo, du kupe-muanenguba, et du Nkam, Compte rendu de mission, CIRAD/IRAD Cameroun, Avril, $52 \mathrm{p}$.

20. Shepherd, A. W., \& Farolfi, S. (1999). Libéralisation du secteur des cultures d'exportation en Afrique. Bilan. Bulletin des services agricoles de la FAO, Rome, $104 \mathrm{p}$.

21. Tchékoté, H., Moulende, T. F., Tallet, B., Guillermou, Y., Yemmafouo, A. (2016). Savoirs et politiques de financement rural en Afrique subsaharienne. Des questionnements à quelques perspectives pour les entrepreneurs ruraux africains. Éditions CLÉ, Yaoundé, 447 p.

22. Tefang Tchomfang, A-F., Bidzanga N., \& Havard, M. (2008). Emergence et évolutions des exploitations familiales agricoles dans le centre Cameroun, ResearchGate, $15 \mathrm{p}$.

23. Uwizeyimana, L. (2009). Après le café, le maraîchage? Mutation des pratiques agricoles dans les hautes terres de l'Ouest Cameroun, Le Cahiers d'Outre-Mer, N ${ }^{\circ} 247$ (juillet-septembre 2009), Montagnes tropicales et transformation des systèmes de production agropastoraux, p. 331-344. 